УДК 658.1

\title{
ОЦІНЮВАННЯ РІВНЯ ПРИБУТКОВОСТІ БАНКІВСЬКОї ГРУПИ
}

\section{ASSESSING THE PROFITABILITY OF THE BANKING GROUP}

\author{
Прокопович Леонід Борисович \\ кандидат економічних наук, доцент, \\ Національний університет кораблебудування імені адмірала Макарова \\ ORCID: https://orcid.org/0000-0003-2561-8862 \\ Баланенко Олена Георгіївна \\ старший викладач, \\ Національний університет кораблебудування імені адмірала Макарова \\ ORCID: https://orcid.org/0000-0002-0021-1516 \\ Колодка Андрій Олександрович \\ магістрант, \\ Національний університет оборони України імені Івана Черняховського \\ ORCID: https://orcid.org/0000-0002-6843-4724 \\ Prokopovich Leonid, Balanenko Olena \\ Admiral Makarov National University of Shipbuilding \\ Kolodka Andrii \\ The National Defence University of Ukraine named after Ivan Cherniakhovskyi
}

\begin{abstract}
Стаття присвячена актуальній проблемі підвищення достовірності оцінювання рівня прибутковості на прикладі банківської групи. Показано, що більшість розроблених раніше моделей прогнозування рівня прибутковості засновані на лінійній регресії, без їх порівняння з нелінійними моделями. У роботі був проаналізований характер існуючої залежності рівня прибутковості банківської групи від показників двох учасників даної групи. Побудовано комплекс однофракторних регресійних моделей рівня прибутковості банківської групи 3 використанням показників кожного учасника групи. 3 метою підвищення якості отриманих моделей було вирішено використовувати методу машинного вчення. Як такий метод був обраний баггинг, який дозволив запропонувати двохфакторну модель оцінювання рівня прибутковості банківської групи.
\end{abstract}

Ключові слова: прибутковість, банківська група, регресія, баггинг, машинне вчення.

Статья посвящена актуальной проблеме повышения достоверности оценивания уровня прибыльности на примере банковской группы. Показано, что большинство разработанных ранее моделей прогнозирования уровня прибыльности основаны на линейной регрессии, без их сравнения с нелинейными моделями. В работе был проанализирован характер существующей зависимости уровня прибыльности банковской группы от показателей двух участников данной группы. Построен комплекс однофакторных регрессионных моделей уровня прибыльности банковской группы с использованием показателей каждого участника группы. С целью повышения качества полученных моделей было решено использовать методы машинного обучения. В качестве такого метода был выбран баггинг, который позволил предложить двухфакторную модель оценивания уровня прибыльности банковской группы.

Ключевые слова: прибыльность, банковская группа, регрессия, баггинг, машинное обучение.

The article is devoted to the current problem of improving the reliability of profitability assessment using the example of a banking group. It has been shown that most previously developed profitability level prediction models are based on linear regression, without comparing them with non-linear models. In the work, the nature of the existing dependence of the level of profitability of the banking group on the performance of two participants in this group was analyzed. The construction of the correlation matrix and the inverse to it made it possible to identify a high level of dependence between the profitability levels of the members of the banking group. Therefore, a set of one-factor 
regression models of the profitability level of the banking group was built using the indicators of each group member separately from the other. Based on the information of each group, a linear, logarithmic and polynomial model was built. The best models for each member of the banking group were selected based on the determination factor, the Fisher criterion, and the average absolute error percentage. It was revealed that for one member of the banking group, the best model for predicting profitability was the polynomial model, for another - linear. Based on the selected models, a model was built that gives an average estimate from these models. In order to improve the quality of the models obtained, it was decided to use machine learning methods. Bagging was chosen as this method. A flowchart of the use of bagging to improve the quality of previously developed models was proposed. To implement the proposed algorithm, a Python program was developed using the Scikit-learn machine learning library. Using this method of machine learning made it possible: to find out the optimal number of samples for each of the selected models, to improve the quality of the developed models and to offer a two-factor model for assessing the profitability level of the banking group. The developed set of models can be used to assess the level of profitability and predict the impact of management decisions on the results of banking groups. It is proposed to use other methods of machine learning, such as a genetic algorithm and a random forest, when building future models.

Keywords: profitability, banking group, regression, bagging, machine learning.

Постановка проблеми. Одним з важливих економічних показників, які характеризують ефрективність діяльності суб'єкта господарювання є прибутковість. Даний показник, разом з іншими, відображає фрінансові можливості щодо впровадження економічної стратегії досягнення цілей суб‘єктом господарювання. В умовах кризових явищ в економіці країни динаміка прибутковості $\epsilon$ впливовим показником, тому що він $€$ відносним показником який, на відміну від прибутку, характеризує не одноразовий результат від прийнятих управлінських рішень. Прийняття багатьох стратегічних рішень та аналіз їх впливу на прибутковість неможливо без оцінки рівня прибутковості суб‘єкту господарювання.

Аналіз останніх досліджень і публікацій. Питання прибутковості розглядали в своїхпрацях таки дослідники як Духновська Л.М., Павлов В.С. [3], Оксенюк Т.М. [6], Стригуль Л.С., Тур Г.Є., Нгуєн Т.М.Х. [8]. Безпосередньо проблемам оцінки прибутковості присвячені дослідження Амбарчян М. [1], Ковальчук Н.О. [5], Сисоєву І.М. [7], Шапран Є.М., Сергієнко О.А., Білоцерківського О.Б. [9]. Проте, проблема достовірності оцінювання рівня прибутковості залишається не вирішеною. Більшість фрахівців, які з метою прогнозування рівня прибутковості розробляли економічні моделі, використовували при побудові моделі лінійну регресію, без ії порівняння із нелелійними моделями.

Метою статті $€$ підвищення достовірності оцінювання рівня прибутковості на прикладі банківської групи.

Виклад основного матеріалу. При проведені дослідження в якості початкових даних були використані показники які наведені у публікації Амбарчян М. [1, с. 88]. Де наведена інфрормація про рівень прибутковості банківської групи «Pekao SA» (Y) та інформація про рівень прибутковості двох учасників даної групи $\left(\mathrm{X}_{1}, \mathrm{X}_{2}\right)$. Відповідно до вказаних початкових даних, розглянемо побудову моделі прогнозування рівня прибутковості банківської групи (Y).

3 метою відбору факторів, для побудови моделі була побудована кореляційна матриця (див. табл. 1). Можна побачити, що рівень прибутковості банківської групи «Pekao SA» майже однаково залежить від рівнів прибутковості учасників груп 1 та 2. Проте, дані табл. 1 свідчать, що між рівнями прибутковості учасників обох груп існує сильний кореляційний зв'язок $(0,994)$.

Таблиця 1

Кореляційна матриця

\begin{tabular}{|c|c|c|c|}
\hline & $Y$ & $X_{1}$ & $X_{2}$ \\
\hline$Y$ & 1 & 0,996903 & 0,996946 \\
\hline$X_{1}$ & 0,996903 & 1 & 0,994311 \\
\hline$X_{2}$ & 0,996946 & 0,994311 & 1 \\
\hline
\end{tabular}

Останнє свідчить про наявність між фракторами мультиколінеарності, що і підтверджує розрахунок зворотної матриці від матриці парних кореляцій вказаних фракторів (див. табл. 2). Значення на головній діагоналі зворотної матриці $(88,14)$ більше 4 , це й говорить про наявність мультиколінеарності.

Зворотна матриця, $\mathbf{R}^{-1}$

Таблиця 2

\begin{tabular}{|c|c|}
\hline 88,14476 & $-87,6433$ \\
\hline$-87,6433$ & 88,14476 \\
\hline
\end{tabular}

Приймаючи доувагивказане, булоприйнято рішення про те, що для подальшого аналізу прибутковості банківської групи «Pekao SA» спробуємо побудувати односракторні регресійні моделі, окремо з фрактором $\mathrm{X}_{1}$ та окрема із фрактором $\mathrm{X}_{2}$. 
Таблиця 3

p-значення

\begin{tabular}{|c|c|c|c|c|c|c|}
\hline \multirow{3}{*}{$\begin{array}{l}\text { Коефрі- } \\
\text { цієнти }\end{array}$} & \multicolumn{3}{|c|}{ Моделі із фактором $\mathrm{X}_{1}$} & \multicolumn{3}{|c|}{ Моделі із фактором $\mathrm{X}_{2}$} \\
\hline & Лінійна & $\begin{array}{c}\text { Логарифр- } \\
\text { мічна }\end{array}$ & $\begin{array}{l}\text { Поліно- } \\
\text { міальна }\end{array}$ & Лінійна & $\begin{array}{c}\text { Логарифр- } \\
\text { мічна }\end{array}$ & $\begin{array}{l}\text { Поліно- } \\
\text { міальна }\end{array}$ \\
\hline & $\begin{array}{l}\text { фрормула } \\
\text { (1) }\end{array}$ & $\begin{array}{c}\text { формула } \\
\text { (2) }\end{array}$ & $\begin{array}{c}\text { формула } \\
\text { (3) }\end{array}$ & $\begin{array}{c}\text { фрормула } \\
\text { (4) }\end{array}$ & $\begin{array}{l}\text { фрормула } \\
\text { (5) }\end{array}$ & $\begin{array}{c}\text { форммула } \\
\text { (6) }\end{array}$ \\
\hline$a_{0}$ & $6,687 \mathrm{E}-08$ & $5,900 \mathrm{E}-13$ & 0,0004 & $5,156 \mathrm{E}-08$ & $2,5226 \mathrm{E}-07$ & 0,147 \\
\hline$a_{1}$ & $4,010 \mathrm{E}-10$ & $4,490 \mathrm{E}-11$ & $6,762 \mathrm{E}-05$ & 3,791 E-10 & 1,040 E-09 & 0,229 \\
\hline$a_{2}$ & - & - & 0,005 & - & - & 0,625 \\
\hline
\end{tabular}

Порівняння моделей

\begin{tabular}{|c|c|c|c|c|c|}
\hline \multirow[b]{2}{*}{ Фактор } & \multirow[b]{2}{*}{ Модель } & \multirow{2}{*}{$\begin{array}{c}\text { Коесріцієнт } \\
\text { детермінації, } \\
\text { R }^{2}\end{array}$} & \multicolumn{2}{|c|}{ Критерій Фішера, F } & \multirow{2}{*}{$\begin{array}{c}\text { Середній } \\
\text { абсолютний } \\
\text { відсоток } \\
\text { помилки, МАРЕ }\end{array}$} \\
\hline & & & розрахунковий & табличний & \\
\hline \multirow{3}{*}{$X_{1}$} & Лінійна & 0,994 & 1285,55 & 5,318 & 2,53 \\
\hline & Логарифрмічна & 0,996 & 2227,59 & 5,318 & 2,063 \\
\hline & Поліноміальна & 0,998 & 1912,98 & 4,737 & 1,85 \\
\hline \multirow{2}{*}{$X_{2}$} & Лінійна & 0,994 & 1303,715 & 5,318 & 3,125 \\
\hline & Логарифрмічна & 0,992 & 1011,397 & 5,318 & 3,565 \\
\hline
\end{tabular}

При дослідженні впливу фрактору $\mathrm{X}_{1}$ на залежну змінну були отримані лінійна, логарисрмічна та поліноміальна моделі, які наведені у фрормулах (1-3).

$$
\begin{gathered}
\hat{y}=2,084+1,529 x_{1}+\varepsilon, \\
\hat{y}=4,167+1,247 \ln \left(x_{1}\right)+\varepsilon, \\
\hat{y}=1,285+2,977 x_{1}-0,363 x_{1}^{2}+\varepsilon,
\end{gathered}
$$

що стосується впливу фрактору $\mathrm{X}_{2}$, то побудовані моделі наведені у фрормулах (4-6).

$$
\begin{gathered}
\hat{y}=2,121+0,609 x_{2}+\varepsilon, \\
\hat{y}=2,012+1,216 \ln \left(x_{2}\right)+\varepsilon, \\
\hat{y}=1,617+0,995 x_{2}-0,039 x_{2}^{2}+\varepsilon,
\end{gathered}
$$

3 метою перевірки значимості параметрів запропонованих моделей скористаємося величинами $p$-значень, які наведені у табл. 3.

Величини р-значень (див. табл. 3) у всіх моделях, крім останньої, менше 0,5, це каже про те, що наведені у моделях (1-5) параметри є значимими. Проте параметри моделі 6 не $є$ значимими, тому далі ця модель не буде використовуватися.

Порівняння запропонованих моделей наведено у табл. 4. Величина коефріцієнту детермінації у всіх моделях перевішує 0,95 , що говорить про високу точність апроксимації. Так як розрахунковий коефіцієнт Фішера за всіма моделями перевищує табличні значення, це визнає статистичну значимість отриманих рівнянь регресії.
Можна побачити, що найбільш якісною між всіма моделями $є$ поліноміальна для фрактору $\mathrm{X}_{1}$ (див. формулу 3). При використанні фрактору $\mathrm{X}_{2}$ для прогнозування величини залежної змінної найбільш оптимальною $є$ лінійна модель (див. фрормулу 4), проте вона за своєю точністю трохи гірше ніж поліноміальна модель для фрактору $\mathrm{X}_{1}$.

Використовуючи моделі 3 та 4 можна побудувати модель, яка дає середню оцінку надану вказаними моделями (див. формулу 7), що дозволить використати в моделі прогнозування рівня прибутковості банківської групи «Pekao SA» обидва фрактори.

$$
\hat{y}=\frac{f\left(x_{1}\right)+f\left(x_{2}\right)}{2}+\varepsilon,
$$

Результат прогнозу за запропонованою моделлю та визначення середньої абсолютної помилки моделі (МАРЕ) наведені у табл. 5.

Як можна побачити, середній абсолютний відсоток помилки (МАРЕ) запропонованої моделі трохи гірше ніж результат моделі 3 $(1,85<2,038)$, проте модель 7 має право на існування так як приймає до уваги вплив обох оракторів. Тому, були зроблені заходи щодо підвищення якості запропонованої моделі. Для чого вирішено підвисити точність моделей 3 та 4 за рахунок застосування одного з методів машинного навчання - баггінгу. Баггінг (bagging) $€$ «скорочення bootstrap aggregating - агрегування бутстраповських вибірок, або пакетне середнє» [2]. 
Визначення середньої абсолютної помилки моделі 7

\begin{tabular}{|c|c|c|c|c|}
\hline$f\left(x_{1}\right)$ & $f\left(x_{2}\right)$ & $\hat{y}$ & $y$ & $\begin{array}{c}\text { Абсолютний } \\
\text { відсоток помилки }\end{array}$ \\
\hline 7,19 & 7,08 & 7,13 & 7,23 & 1,32 \\
\hline 7,06 & 7,25 & 7,15 & 7,01 & 2,06 \\
\hline 7,24 & 7,22 & 7,23 & 7,28 & 0,69 \\
\hline 7,01 & 7,09 & 7,05 & 7,04 & 0,10 \\
\hline 7,28 & 7,14 & 7,21 & 7,21 & 0,01 \\
\hline 7,17 & 7,17 & 7,17 & 7,18 & 0,19 \\
\hline 3,39 & 3,16 & 3,27 & 3,26 & 0,44 \\
\hline 3,04 & 2,95 & 3,00 & 3,09 & 3,06 \\
\hline 2,84 & 3,07 & 2,95 & 2,73 & 8,23 \\
\hline 2,99 & 3,08 & 3,03 & 3,17 & 4,28 \\
\hline
\end{tabular}

Моделі за результатами машинного навчання

\begin{tabular}{|l|c|c|c|}
\hline \multicolumn{1}{|c|}{ Модель } & Фактор & $\begin{array}{c}\text { Кількість } \\
\text { бутстраповських } \\
\text { вибірок }\end{array}$ & МАРE \\
\hline Поліноміальна & $\mathrm{X}_{1}$ & 160 & 1,82 \\
\hline Лінійна & $\mathrm{X}_{2}$ & 350 & 2,93 \\
\hline
\end{tabular}

Загальна схема побудови моделі за допомогою баггінгу наведена на рис. 1. Для реалізації наведеного алгоритму була розроблена програма на мові Python із використанням спеціальної бібліотеки для машинного навчання Scikit-learn, за допомогою якої були побудовані рівняння регресії для кожної із бутстраповських вибірок.

За результатами машинного навчання було 3'ясовано оптимальну кількість бутстраповських вибірок для кожної моделі (див. табл. 6), в наслідок чого була побудована модель наведена у формулі 8. Розрахунок показника MAPE для даної моделі наведений у табл. 7.

$$
\hat{y}=\frac{\left(\hat{f}_{1}\left(x_{1}\right)+\hat{f}_{2}\left(x_{1}\right)+\ldots \hat{f}_{160}\left(x_{1}\right)\right) / 160^{+}\left(\hat{f}_{1}\left(x_{2}\right)+\hat{f}_{2}\left(x_{2}\right)+\ldots \hat{f}_{350}\left(x_{2}\right)\right) / 350}{2}+\varepsilon
$$

Таблиця 7

Визначення середньої абсолютної помилки моделі 8

\begin{tabular}{|c|c|c|}
\hline$\hat{y}$ & $y$ & Відсоток помилки \\
\hline 7,138 & 7,23 & $-1,274$ \\
\hline 7,153 & 7,01 & 2,035 \\
\hline 7,234 & 7,28 & $-0,631$ \\
\hline 7,046 & 7,04 & 0,079 \\
\hline 7,216 & 7,21 & 0,088 \\
\hline 7,167 & 7,18 & $-0,181$ \\
\hline 3,269 & 3,26 & 0,272 \\
\hline 2,991 & 3,09 & $-3,201$ \\
\hline 2,95 & 2,73 & 8,075 \\
\hline 3,03 & 3,17 & $-4,414$ \\
\hline \multicolumn{2}{r}{ MAРE } & 2,025 \\
\hline
\end{tabular}

Висновки. Розроблені лінійні та нелінійні моделі прогнозування рівня прибутковості на прикладі банківської групи. Запропоновані альтернативні моделі, зроблено їх порівняння. За результатами машинного навчання було з'ясовано оптимальну кількість бутстраповських вибірок для кожної 3 відібраних моделей. Використання баггінгу дозволило підвисити якість розроблених моделей та запропонувати двохфакторну модель оцінювання рівня прибутковості банківської групи.

Перспективи подальших досліджень полягають вивчені можливості використання інших методів машинного навчання, таких як генетичний алгоритм та випадковий ліс. 


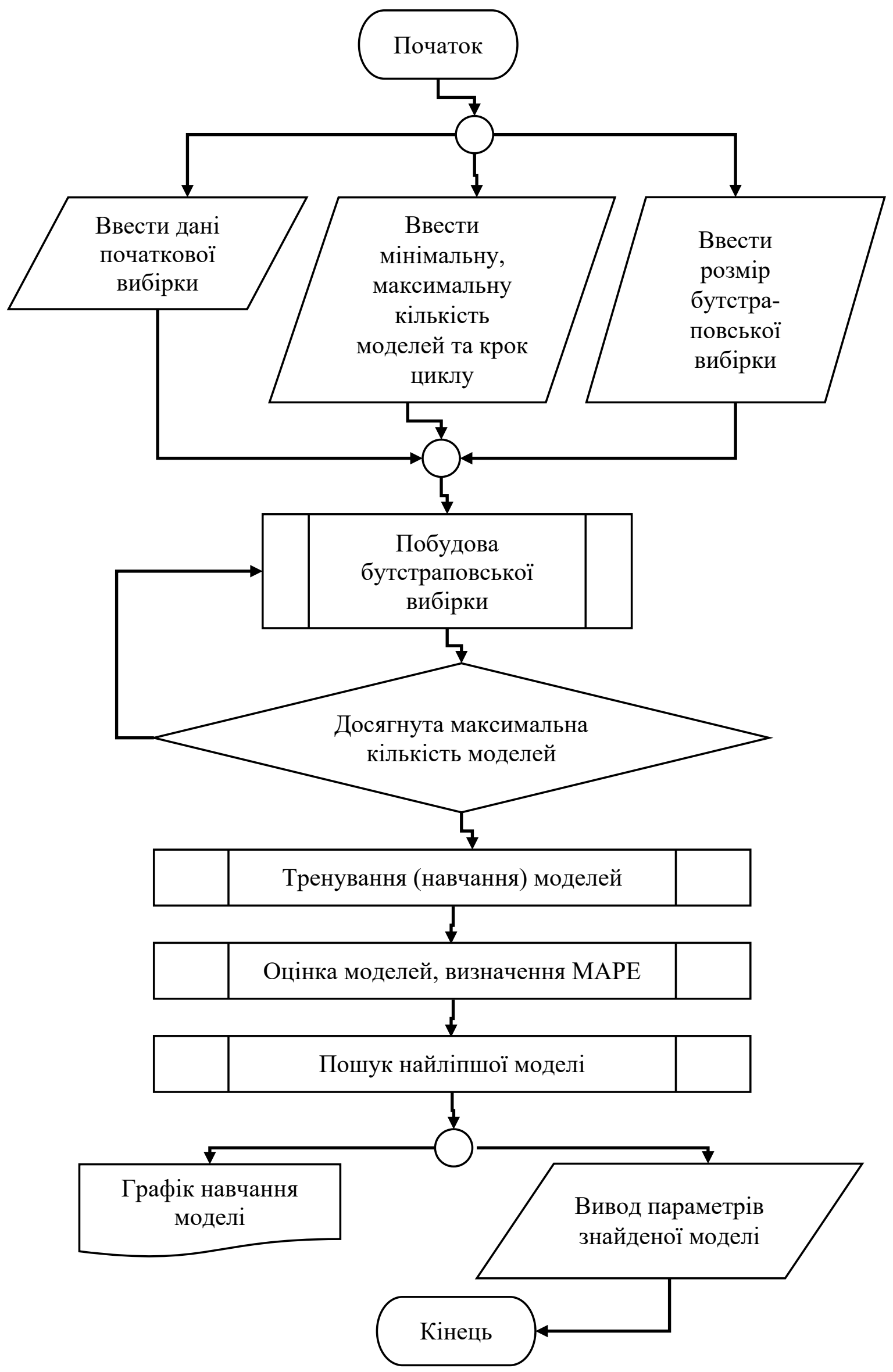

Рис. 1. Блок-схема побудови моделі за допомогою беггінгу 


\section{СПИСОК ВИКОРИСТАНИХ ДЖЕРЕЛ:}

1. Амбарчян М. Регресійна модель рівня прибутковості банківської групи. Вісник КНТЕУ. 2013. № 2. C. 84-97. URL: https://knutd.edu.ua/publications/pdf/Ukrainian_editions/Abramchan20150907.pdf

2. ВандерПлас Дж. Pуthon для сложных задач: наука о данных и машинное обучение. СПб. : Питер, 2018.

3. Духновська Л.М., Павлов В.С. Прибутковість підприємства: сутність та ефективність управління. Науковий вісник Ужгородського національного університету. 2018. № 17. Ч. 1. С. 100-103. URL: http://www.visnyk-econom.uzhnu.uz.ua/archive/17_1_2018ua/24.pdf (дата звернення: 25.01.2022).

4. Єпіфанова І.Ю., Гуменюк В.С. Прибутковість підприємства: сучасні підходи до визначення сутності. Економіка і суспільство. 2016. № 3. С. 189-192. URL: https://economyandsociety.in.ua/journals/3_ukr/33.pdf (дата звернення: 25.01.2022).

5. Ковальчук Н.О. Аналіз динаміки рівня прибутковості підприємств України в умовах викликів сьогодення. Східна Європа: економіка, бізнес та управління. 2019. № 2(19). C. 151-156. URL: http://www.easterneuropeebm.in.ua/journal/19_2019/25.pdf

6. Оксенюк Т.М. Фактори підвищення прибутковості підприємства: еволюційний аспект. Науковий вісник Херсонського державного університету. 2015. № 13. Ч. 3. С. 16-19. URL: http://www.ej.kherson.ua/journal/ economic_13/87.pdf

7. Сисоєва І.М. Прогнозування прибутку підприємства в залежності від методів облікової політики. Економіка та держава. 2010. № 10. C. 93-94. URL: http://www.economy.in.ua/pdf/10_2010/26.pdf

8. Стригуль Л.С., Тур Г.Є., Нгуєн Т.М.Х. Ефективність та прибутковість: теоретичний аспект. Інсраструктура ринку. 2019. № 36. С. 287-292. URL: http://www.market-infr.od.ua/journals/2019/36_2019_ukr/47.pdf

9. Шапран Є.М., Сергієнко О.А., Білоцерківський О.Б. Прогнозування прибутковості підприємства ресторанного бізнесу та чинників впливу на його фінансові показники. Науковий вісник Ужгородського національного універсuтеmy. 2020. № 30. С. 218-223. URL: http://www.visnyk-econom.uzhnu.uz.ua/archive/30_2020ua/44.pdf

\section{REFERENCES:}

1. Ambarchian, M. (2013) Rehresiina model rivnia prybutkovosti bankivskoi hrupy [Regression model of the level of profitability of the banking group]. Visnyk KNTEU, no. 2, pp. 84-97. Retrieved from: https://knutd.edu.ua/publications/pdf/Ukrainian_editions/Abramchan20150907.pdf (in Ukrainian)

2. VanderPlas, J. (2018) Python dlia slozhnыkh zadach: nauka o dannыkh y mashynnoe obuchenye [Python Data Science Handbook: Essential Tools for Working with Data]. SPb.: Pyter. (in Russian)

3. Dukhnovska, L.M., \& Pavlov, V.S. (2018) Prybutkovist pidpryiemstva: sutnist ta efektyvnist upravlinnia [Profitability of the enterprise: the essence and efficiency of management]. Naukovyi visnyk Uzhhorodskoho natsionalnoho universytetu, no. 17 , ch. 1, pp. 100-103. Retrieved from: http://www.visnyk-econom.uzhnu.uz.ua/ archive/17_1_2018ua/24.pdf (in Ukrainian)

4. Yepifanova, I.Yu., \& Humeniuk, V.S. (2016) Prybutkovist pidpryiemstva: suchasni pidkhody do vyznachennia sutnosti [Profitability of the enterprise: modern approaches to determining the essence]. Ekonomika $i$ suspilstvo, no. 3, pp. 189-192. Retrieved from: https://economyandsociety.in.ua/journals/3_ukr/33.pdf (in Ukrainian)

5. Kovalchuk, N.O. (2019) Analiz dynamiky rivnia prybutkovosti pidpryiemstv Ukrainy v umovakh vyklykiv sohodennia [Analysis of the dynamics of the level of profitability of Ukrainian enterprises in the face of current challenges]. Skhidna Yevropa: ekonomika, biznes ta upravlinnia, no. 2(19), pp. 151-156. Retrieved from: http://www.easterneurope-ebm.in.ua/journal/19_2019/25.pdf (in Ukrainian)

6. Okseniuk, T.M. (2015) Faktory pidvyshchennia prybutkovosti pidpryiemstva: evoliutsiinyi aspekt [Factors of increasing the profitability of the enterprise: the evolutionary aspect]. Naukovyi visnyk Khersonskoho derzhavnoho universytetu, no. 13, ch. 3, pp. 16-19. Retrieved from: http://www.ej.kherson.ua/journal/economic_13/87.pdf (in Ukrainian)

7. Sysoieva, I.M. (2010) Prohnozuvannia prybutku pidpryiemstva v zalezhnosti vid metodiv oblikovoi polityky [Profit forecasting of the enterprise depending on accounting policy methods]. Ekonomika ta derzhava, no. 10, pp. 93-94. Retrieved from: http://www.economy.in.ua/pdf/10_2010/26.pdf (in Ukrainian)

8. Stryhul, L.S., Tur, H.Ye., \& Nhuien, T.M.Kh. (2019) Efektyvnist ta prybutkovist: teoretychnyi aspekt [Efficiency and profitability: theoretical aspect]. Infrastruktura rynku, no. 36, pp. 287-292. Retrieved from: http://www.market-infr.od.ua/journals/2019/36_2019_ukr/47.pdf (in Ukrainian)

9. Shapran, Ye.M., Serhiienko, O.A., \& Bilotserkivskyi, O.B. (2020) Prohnozuvannia prybutkovosti pidpryiemstva restorannoho biznesu ta chynnykiv vplyvu na yoho finansovi pokaznyky [Forecasting the profitability of the restaurant business and factors of influence on its financial indicators]. Naukovyi visnyk Uzhhorodskoho natsionalnoho universytetu, no. 30, pp. 218-223. Retrieved from: http://www.visnyk-econom.uzhnu.uz.ua/archive/30_2020ua/44.pdf (in Ukrainian) 